\title{
Field tests using an instrumented model pipe pile in sand
}

\author{
D. Igoe \\ University College Dublin
}

K. Gavin

University College Dublin

B. O'Kelly

Trinity College Dublin

Reference: Igoe D., Gavin K., and O'Kelly B., 2010. Field tests using an instrumented model pipe pile in sand, Proceedings, Seventh International Conference on Physical Modelling in Geotechnics, Zurich, Switzerland, 28th June1st July, 2010, pp775 - 780 .

ABSTRACT: Recent design methods for displacement piles have been developed based on the results of field tests using highly instrumented, closed-ended model piles which were able to measure the radial effective stress at a number of locations along the pile shaft. The measured $\sigma_{r}^{\prime}$ were then directly related to in-situ soil properties such as CPT cone resistance. Many design methods have been extended to consider the shaft resistance developed along open-ended (pipe) piles by adopting various assumptions with regard to differences between the radial stress regimes set up by closed and open-ended piles. However, no comparable measurements of $\sigma_{r}^{\prime}$ from pipe piles were available to assess the validity of these assumptions. This paper presents the results of radial stress measurements made on an instrumented open-ended pile during installation into loose sand. These measurements are used to investigate the validity of some of the assumptions underlying a number of popular design methods.

\section{INTRODUCTION}

The axial load-carrying capacity of an open-ended pipe pile is developed through friction along the internal and external walls of the pile combined with end-bearing resistance directly beneath the pile annulus. Due to the constrained nature of the internal soil core, or soil plug, the majority of the internal friction develops within $2-3$ diameters of the pile toe. The base resistance of an open-ended pile is defined as the combination of the end-bearing stress beneath the pile plug, $\mathrm{q}_{\text {plug }}$, and the pile annulus, $\mathrm{q}_{\mathrm{ann}}$. During installation, an open-ended pile can be fully coring or it can experience various degrees of plugging, preventing the full intrusion of soil into the pile. A plugged pile will cause more displacement and densification to the soil as it penetrates than a fully coring pile, thus generating a higher resistance. The degree of plugging which occurs during installation can be quantified by the Incremental Filling Ratio (IFR) which is defined as the rate of change of height of the soil plug with respect to pile penetration (IFR $=1$ when pile is fully coring and $\mathrm{IFR}=0$ when pile is fully plugged). Laboratory and field studies (Gavin \& Lehane 2003, Xu 2007, Paik \& Lee 1993, and others) have demonstrated that plugging during installation strongly influences both the base and external shaft capacities.

The external unit shaft resistance which can develop along a pile, $\tau_{\mathrm{f}}$, has been shown to be governed by friction and is dependant on the effective horizontal stress during failure, $\sigma_{\text {rf }}^{\prime}$, and the mobilized angle of friction, $\delta$ (Lehane 1992);

$\tau_{\mathrm{f}}=\sigma_{\mathrm{rf}}^{\prime} \cdot \tan \delta$

The evaluation of $\delta$ is possible through simple laboratory testing or it can be estimated using well established correlations with particle size and shaft surface roughness (Uesegi \& Kishida 1986 and others). The estimation of $\sigma_{\text {rf }}^{\prime}$ is an area of greater uncertainty. The use of in-situ site characterization parameters such as the Cone Penetration Test (CPT) in pile design has become popular due to the good correlation between cone resistance, $\mathrm{q}_{\mathrm{c}}$, and the in-situ density. Simple design methodologies (known as 'alpha' methods), which relate $\tau_{\mathrm{f}}$ to CPT $\mathrm{q}_{\mathrm{c}}$ through a scalar coefficient are common but highly empirical. $\mathrm{Nu}-$ merous studies (Meyerhof 1956, Bustamante \& Gianeselli 1979, Foye et al 2009 and others) have recommended differing 'alpha' coefficients. Recent advances in pile design have been achieved through the closed-ended Imperial College Pile (ICP) testing program (Lehane 1992 and Chow 1997) which directly measured the radial effective stresses acting on the pile shaft, thus identifying some of the key mechanisms controlling pile behavior in sand. However, due to geometric constraints associated with instrumenting open-ended piles there are no tests reported to date which have reliably measured the radial effective stress from open-ended piles in sand in a similar manner to the ICP tests. This paper presents measured radial effective stresses from an 
open-ended pile test in loose sand and demonstrates the effect of plugging during installation on these stresses. The validity of certain assumptions made in recent design methods regarding the extrapolation from closed- to open-ended piles are questioned in light of these findings.

\section{BACKGROUND}

Based on radial stress measurements from the closed-ended ICP, Lehane (1992) demonstrated that $\sigma_{\mathrm{rf}}^{\prime}$ comprised of two main components;

$\sigma_{\mathrm{rf}}^{\prime}=\sigma_{\mathrm{rc}}^{\prime}+\Delta \sigma_{\mathrm{rd}}^{\prime}$

where $\sigma_{\text {rc }}^{\prime}$ is the equalized radial effective stress and $\Delta \sigma_{\mathrm{rd}}^{\prime}$ is the increase in radial stress during loading. Lehane et al. (1994) attributed the increase during loading to dilation in a thin interface zone at the pile shaft and showed that $\Delta \sigma_{\text {rd }}^{\prime}$ was inversely dependant on pile diameter and hence small piles would experience significant scale effects. This highlights the importance of directly measuring the radial effective stresses. The ICP tests demonstrated that at a given level along the pile the $\sigma_{\text {rc }}^{\prime}$ varied proportionally with the CPT $\mathrm{q}_{\mathrm{c}}$. Another important finding of these tests was the reduction in measured radial stress with distance from the pile tip (commonly referred to as friction fatigue). These findings, in conjunction with database studies and theoretical modeling, led to the development of two recent CPT design methods, the IC-05 (Jardine et al. 2005) and UWA-05 (Lehane et al. 2005). Similarities between the two methods include the incorporation of an $\mathrm{h} / \mathrm{D}$ parameter (distance form the pile tip, h, normalized by pile diameter, D), expressed as a power function, to account for friction fatigue. However, both approaches use very different methods to extrapolate from closed- to open-ended pile behaviour. Chow (1997), who examined the shaft friction profiles on two open-ended piles in dense sand, proposed substituting the $\mathrm{D}$ parameter with $\mathrm{D}^{*}$ :

$\mathrm{D}^{*}=\sqrt{ }\left(\mathrm{D}^{2}-\mathrm{D}_{\mathrm{i}}^{2}\right)$

where $D_{i}$ is the internal diameter. This approach results in similar radial stresses for closed- and openended piles near the tip, but a stronger rate of decay with distance from the pile tip and fails to take into account the degree of plugging during installation. However, it was argued that due to the difficulty in predicting plugging prior to installation this disadvantage was nullified, and as a result Equation 5a was adopted in the IC-05 method.

White et al. (2005) proposed that there was a stronger logical basis for applying a modification factor to $\mathrm{q}_{\mathrm{c}}$ rather than $\mathrm{h} / \mathrm{D}$. White et al. (2005) explored the possibility of using a function such as the effective area ratio $A_{r, \text { eff }}$ (ratio of volume of displaced soil to the gross pile volume) to account for the reduced soil displacement imposed by an openended pile:

$\mathrm{A}_{\mathrm{r}, \mathrm{eff}}=1-\operatorname{IFR}\left(\mathrm{D}_{\mathrm{i}} / \mathrm{D}\right)^{2}$

The $A_{r, \text { eff }}$ value is unity for a closed-ended pile reducing to zero for an infinitely thin-walled fully coring pile. Using simplified cavity expansion theory, White et al. (2005) demonstrated that the $A_{r, e f f}$ expressed as a power law could be used to extrapolate from closed- to open-ended radial effective stresses. This method allowed for reduced friction along the entire shaft, based on the degree of soil displacement imposed during installation and was subsequently adopted for the UWA-05 design method (see equation $5 b)$.

$\sigma_{\mathrm{rc}}^{\prime}=0.016 \cdot \mathrm{q}_{\mathrm{c}} \cdot\left(\mathrm{h} / \mathrm{D}^{*}\right)^{-0.38} \cdot\left(\sigma_{\mathrm{v} 0}^{\prime} / \mathrm{P}_{\mathrm{atm}}\right)^{0.12}$

$\sigma_{\mathrm{rc}}^{\prime}=0.03 \cdot \mathrm{q}_{\mathrm{c}} \cdot(\mathrm{h} / \mathrm{D})^{-0.5} \cdot \mathrm{A}_{\mathrm{r}, \mathrm{eff}}^{0.3}$

where $\mathrm{P}_{\text {atm }}$ is the atmospheric pressure $(\approx 100 \mathrm{kPa})$. Both design methods incorporate a minimum h/D value which prevents an overly dramatic increase of $\sigma_{\text {rc }}^{\prime}$ near the pile tip. It is important to note that for both methods there is an increased $\sigma^{\prime}{ }_{r c}$ near the pile tip, even for coring piles which have a low $A_{r, e f f}$ (see Figure 1).

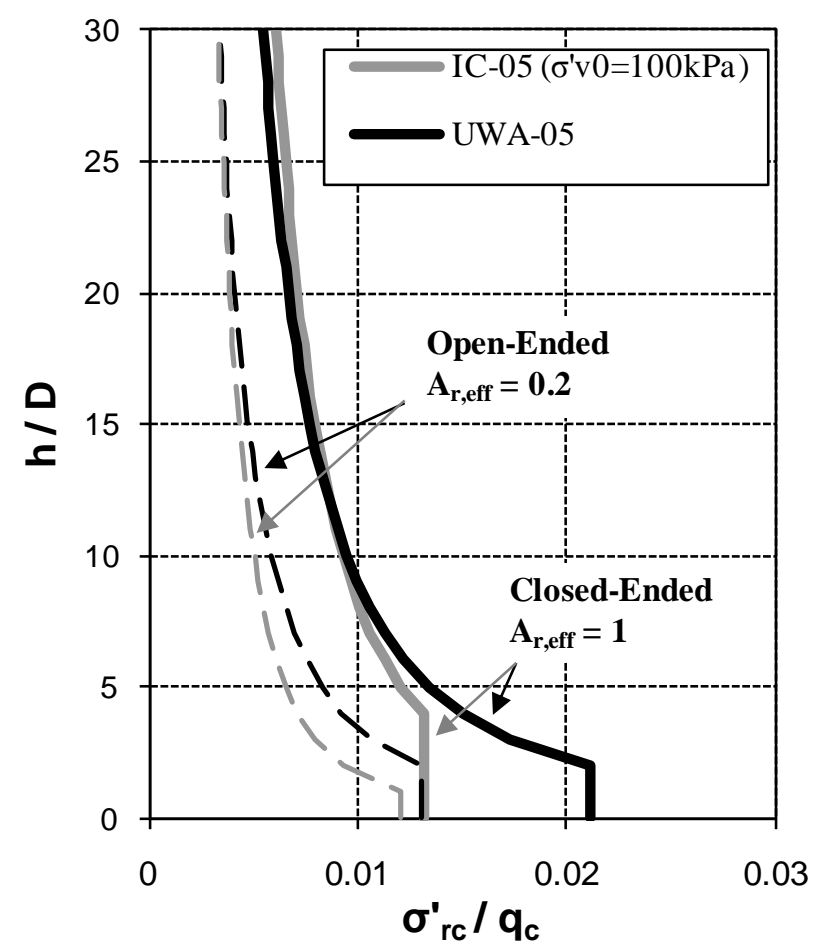

Figure. 1 External shaft friction profiles derived for recent CPT design methods for piles in sand

\section{DESCRIPTION OF EXPERIMENTS}

\subsection{Site Conditions}

The test site discussed in this paper is a sand quarry, situated at Blessington, $25 \mathrm{~km}$ southwest of Dublin. The natural in-situ material is a heavily over- 
consolidated, glacially derived, very dense, fine sand deposit with close to $100 \%$ relative density and a CPT $\mathrm{q}_{\mathrm{c}}$ resistance in the range of $15-20 \mathrm{MPa}$. Given the high CPT $\mathrm{q}_{\mathrm{c}}$ values at the site, the pile could not be installed in the natural ground. To overcome this, a large $2.5 \mathrm{~m}$ wide, $10 \mathrm{~m}$ long and $6 \mathrm{~m}$ deep trench was excavated at the site. The excavated material was backfilled into the trench maintaining a minimum drop-height of $1 \mathrm{~m}$. Eight CPTs conducted in the trench verified the formation of a uniform deposit of loose sand. The average CPT $\mathrm{q}_{\mathrm{c}}$ is shown in Figure 2. Up to $1.5 \mathrm{~m}$ depth the trench was compacted by the CPT rig and general quarry trafficking, which is reflected in the $\mathrm{q}_{\mathrm{c}}$ profile. Below this level the CPT $\mathrm{q}_{\mathrm{c}}$ was relatively consistent between 0.8 and $1 \mathrm{MPa}$ until the base of the trench was approached at $\approx 6 \mathrm{~m}$ depth.

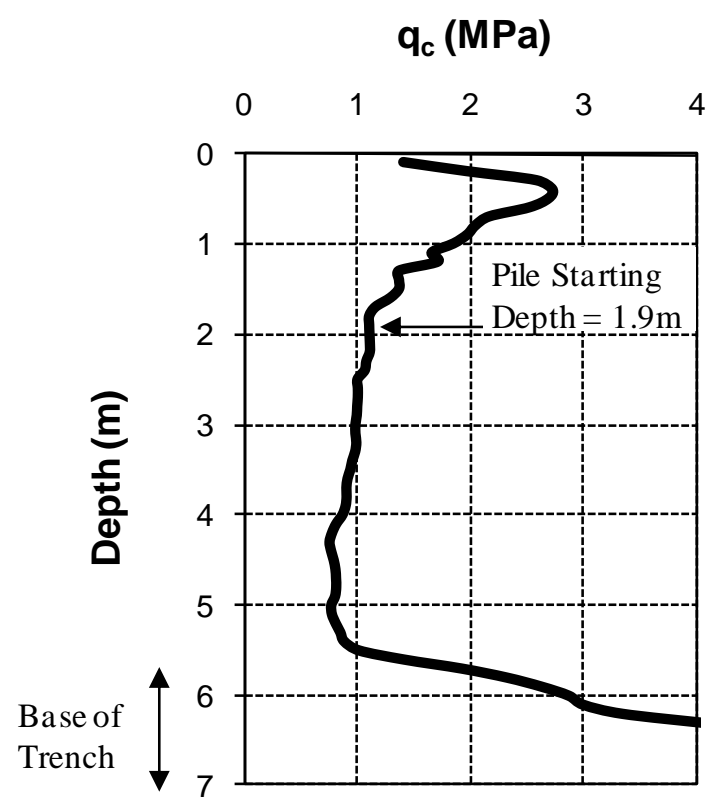

Figure 2. Average CPT $\mathrm{q}_{\mathrm{c}}$ in Trench

\subsection{The UCD Instrumented Model Pile}

The UCD open-ended model pile is constructed using the twin-wall design, pioneered by Paik \& Lee (1993), which allows for the separation of the internal and external shaft loads (Figure 3 ). The pile has an external diameter (D) of $168 \mathrm{~mm}$ and a wall thickness $(\mathrm{t})$ of $9 \mathrm{~mm}$ giving a $\mathrm{D} / \mathrm{t}$ ratio of $\approx 19$ in line with piles used offshore (typically $15-45$ ). This results in the pile having an $A_{r, \text { eff }}=0.2$ when fully coring. The pile consists of an instrumented section $2 \mathrm{~m}$ in length and a series of $0.8 \mathrm{~m}$ long interlocking extension pieces which can increase the pile length to $6 \mathrm{~m}$. The total radial stress and pore pressure sensors were mounted diametrically apart at $\mathrm{h} / \mathrm{D}$ spacings of $1.5,5.5$ and 10.5 . Electrical resistance strain gages, which were bonded to the inner and outer wall surfaces at different levels along the length of the pile, allowed for the independent measurement of the loads taken by outer shaft, internal plug and pile annulus throughout testing.

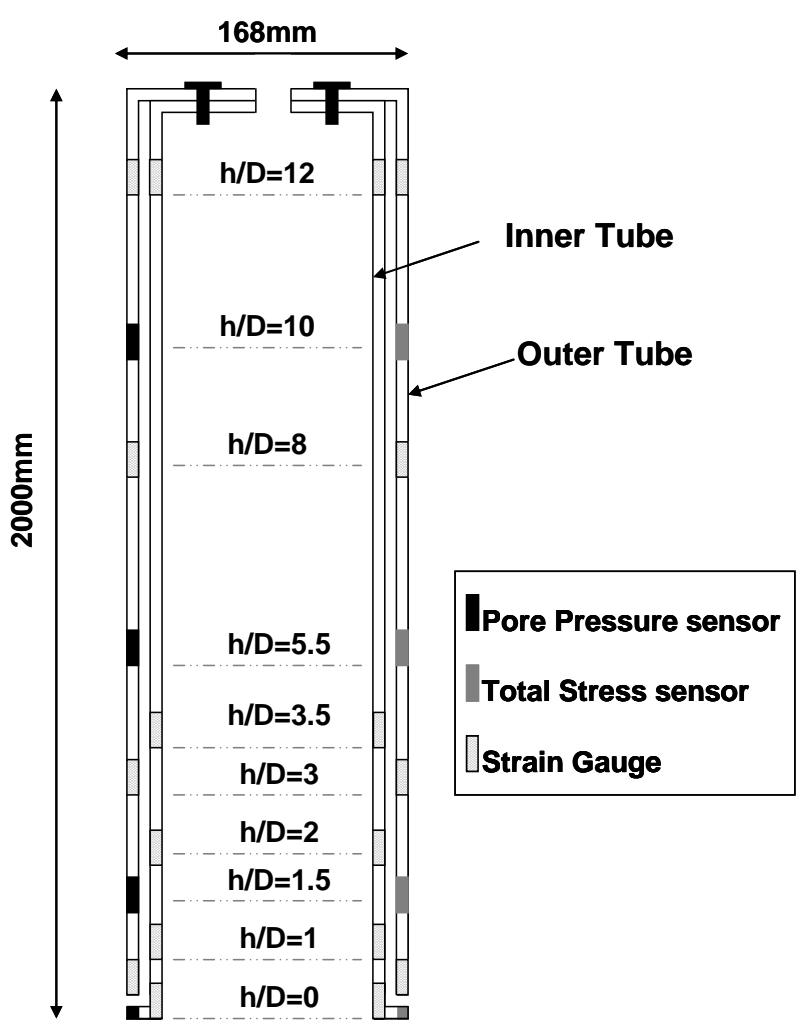

Figure 3. UCD open-ended model pile (after Igoe et al, 2010)

\subsection{Testing Overview}

The pile was jacked using a 20 tonne CPT rig as a reaction, from a $1.9 \mathrm{~m}$ deep starting hole to a final depth of $5.9 \mathrm{~m}$. The truck's hydraulic rams (which push at a constant rate of $20 \mathrm{~mm} / \mathrm{s}$ ) were used to jack the pile in $100 \mathrm{~mm}$ strokes with the load being completely removed between each stroke to allow measurement of the plug length and stationary horizontal stress values.

\section{EXPERIMENTAL RESULTS}

\subsection{Plugging Response}

The IFR profile measured during installation is shown in Figure 4. The pile was fully coring (IFR $\approx$ $100 \%$ ) for the first $0.1 \mathrm{~m}$ jacking stroke, and then experienced significant plugging and became fully plugged at a penetration (relative to the base of the starter hole) of $1.1 \mathrm{~m}$. The pile remained plugged until the final two jacking strokes of installation where the IFR value began to increase and the pile reverted to partially plugged penetration. This occurred as the pile approached the bottom of the trench and the plug begins to 'sense' the very dense natural in-situ material beneath it. Other tests on jacked piles in strongly layered ground (Finlay et al. 2001) show a similar full plugging response after $\approx 5 \mathrm{D}$ of penetration in uniform soils but become unplugged as a more dense layer was approached. 


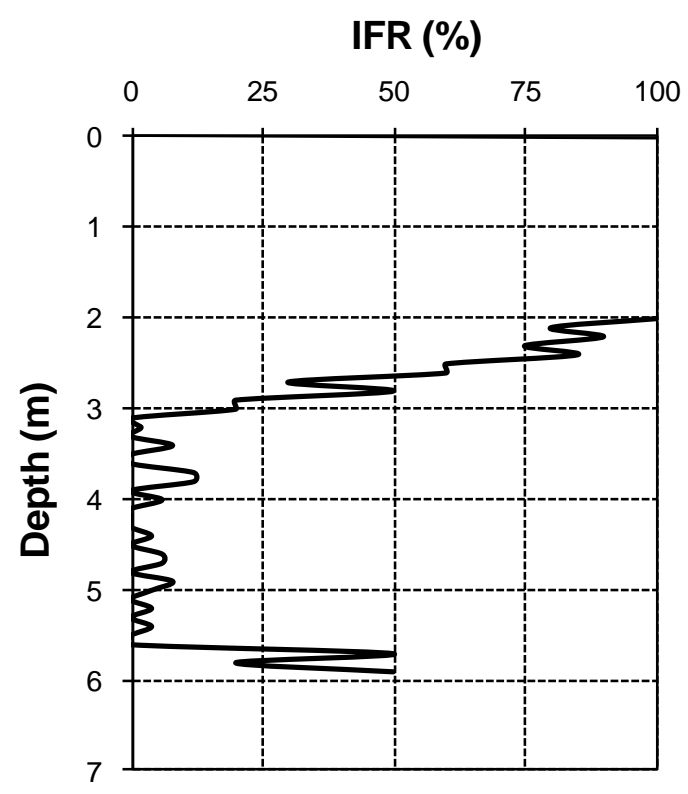

Figure 4. Plugging response during installation

\subsection{Installation Resistance}

The total load and separated base and shaft resistances measured during installation are shown in Figure 5. The total load increased sharply up to 3.3 $m$ depth, mainly due to the dramatic increase in base resistance up to this depth, as IFR reduces and the pile becomes plugged. Below this depth, the pile was fully plugged and the base resistance became steady, up to $\approx 5.6 \mathrm{~m}$ depth, after which it began to increase again in response to the dense soil at the bottom of the trench. The shaft resistance increased slowly up to $3.6 \mathrm{~m}$ depth, after which the increase becomes steeper, reaching $12 \mathrm{kN}$ at the end of installation. This is attributed to the lower shaft entering the region where the pile had penetrated in the fully plugged condition (IFR $=0$ ) and the soil had experienced a relatively high level of pre-stress.

\subsection{Radial Effective Stresses during Installation}

As the entire pile test was conducted above the water table $(\approx 8 \mathrm{~m}$ depth), the pore water pressures measured during installation were negligible. Consequently, the stationary radial effective stresses, measured during installation when the pile was unloaded, are equivalent to the long term equalized radial effective stresses, $\sigma_{\text {rc }}^{\prime}$, and are shown in Figure 6. During transport the sensor at $h / D=10$ was damaged and this did not respond throughout testing. The $\sigma_{\text {rc }}^{\prime}$ values at the two working sensor locations increased progressively until the sensor reached $3.1 \mathrm{~m}$ depth (where the pile had become fully plugged) after which the values steadied off. At the end of installation, at $5.6 \mathrm{~m}$ depth, the $\sigma_{\mathrm{rc}}^{\prime}$ at $\mathrm{h} / \mathrm{D}=1.5$ reduced sharply, coinciding with when the pile became unplugged. The relatively uniform nature of the CPTs below $2 \mathrm{~m}$ depth suggest the increase in $\sigma_{\text {rc }}^{\prime}$ values between 2 and $3.1 \mathrm{~m}$ is primari- ly due to the decrease in IFR and the onset of plugging.

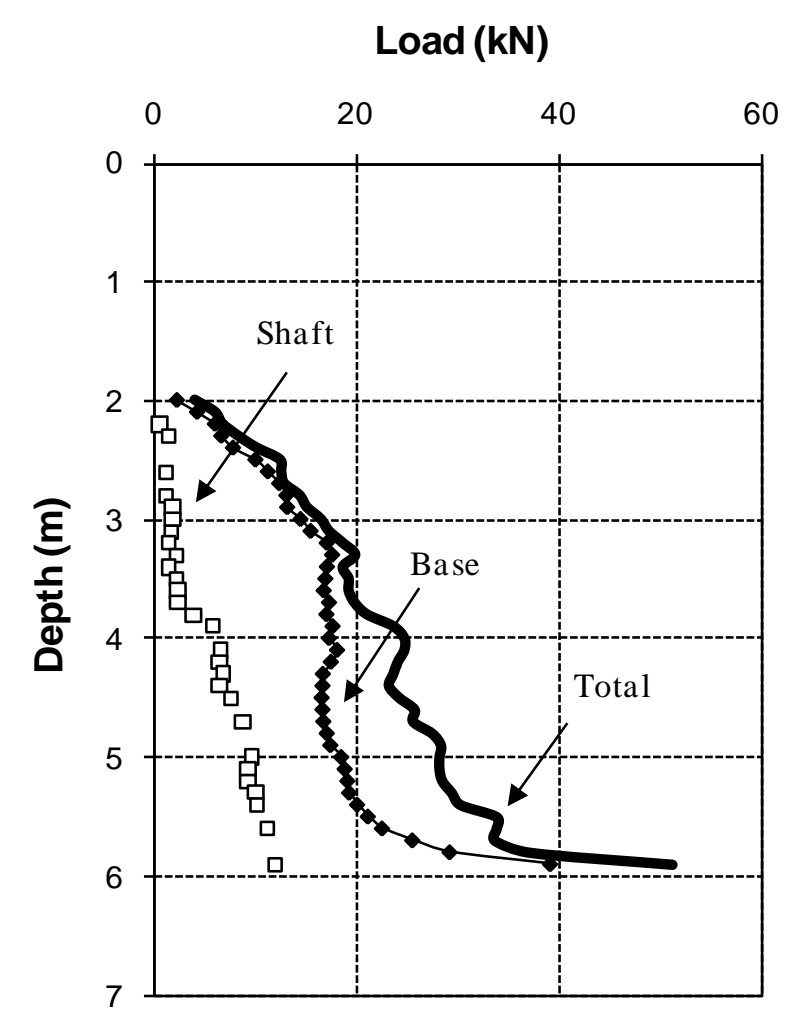

Figure 5. Installation resistance

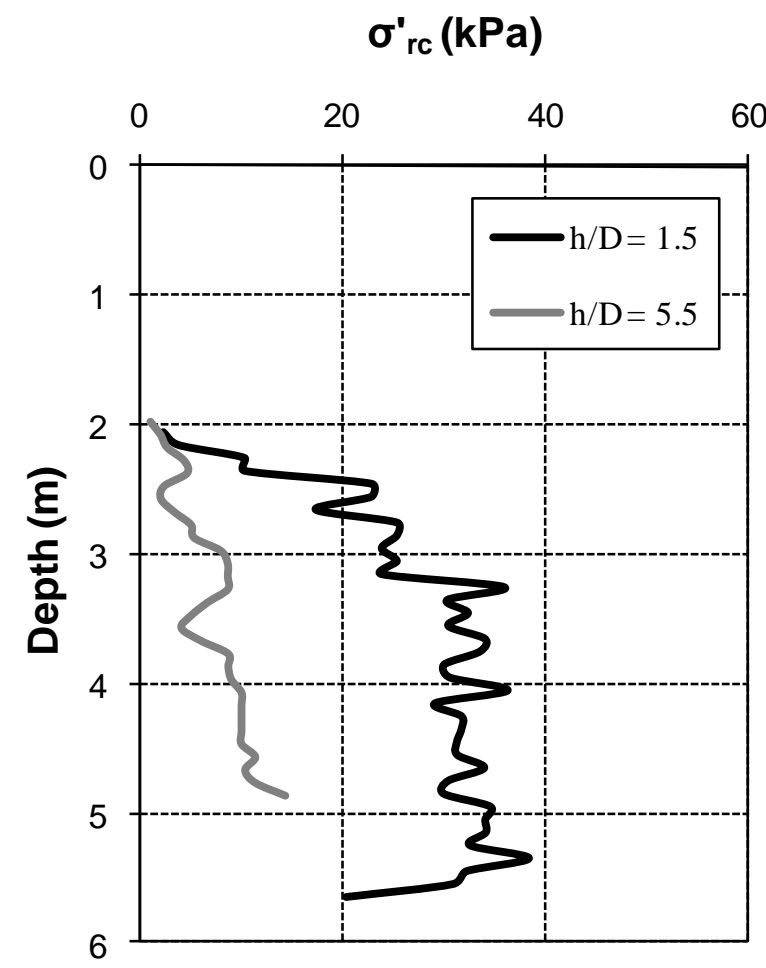

Figure 6. Equalized radial effective stress profile

\section{DISCUSSION}

To examine the affect of plugging on the equalized effective radial stress at any given level along the pile, the measured $\sigma_{\text {rc }}^{\prime}$ values are normalized by the CPT $\mathrm{q}_{\mathrm{c}}$ and plotted against the effective area ratio of 
the pile at that depth (see Figure 7). The trend for $\sigma_{\mathrm{rc}}^{\prime} / \mathrm{q}_{\mathrm{c}}$ to increase with increasing $\mathrm{A}_{\mathrm{r}, \mathrm{eff}}$ at both sensor locations is evident. When the pile was fully coring $\left(\mathrm{IFR}=100 \%, \mathrm{~A}_{\mathrm{r}, \mathrm{eff}}=0.2\right)$ the $\sigma_{\mathrm{rc}}^{\prime} / \mathrm{q}_{\mathrm{c}} \approx 0.003$ at both levels. Near the pile tip at $\mathrm{h} / \mathrm{D}=1.5$, the $\sigma_{\mathrm{rc}}^{\prime} / \mathrm{q}_{\mathrm{c}}$ values increase as the pile becomes plugged reaching 0.03 when $A_{r, e f f}=1 \quad(I F R=0 \%)$, increasing to 0.04 when the pile has been pushed continuously in a fully plugged manner. When the pile became unplugged and the IFR increases at the end of installation, the $\sigma_{\mathrm{rc}}^{\prime} / \mathrm{q}_{\mathrm{c}}$ reduced and provided a good match with the trend in the data. Further back up the shaft, at $\mathrm{h} / \mathrm{D}=5.5$, the $\sigma_{\mathrm{rc}} / \mathrm{q}_{\mathrm{c}}$ increases from $\approx 0.003$ when fully coring to 0.01 at the onset of plugging, reaching 0.015 after continuous fully plugged penetration.

It was evident that the effect of plugging on $\sigma_{\mathrm{rc}}^{\prime}$ was most pronounced near the pile tip and reduced with distance up the shaft. When the pile was fully coring the $\sigma^{\prime}{ }_{\mathrm{rc}} / \mathrm{q}_{\mathrm{c}}$ values near the pile tip and further up the shaft were approximately equal. The authors suggest that low-displacement piles (where $A_{r, e f f}<$ 0.3 ) only generate radial stresses which are at a lower-bound value which is controlled by the far field soil. Hence the normalized radial effective stress distributions is relatively constant along the entire shaft. In this case it may be logical to use simple 'alpha' approaches which relate $\tau_{\mathrm{f}}$ to $\mathrm{q}_{\mathrm{c}}$ through a scalar coefficient and hence assume a constant radial stress profile (however the choice of 'alpha' coefficient remains an area of contention).

However, a pile penetrating in a partial or fully plugged manner (with a high degree of soil displacement and higher $A_{r, e f f}$ ) will develop high radial stresses near the pile tip which will reduce with distance from the pile tip due to the effects of friction fatigue. The authors suggest that at some distance remote from the pile tip, if enough load cycles have been applied, the radial stresses of full-displacement piles $\left(\mathrm{A}_{\mathrm{r}, \text { eff }}=1\right)$ may reach a minimum value approximating those of low-displacement piles $\left(\mathrm{A}_{\mathrm{r}, \mathrm{eff}}<\right.$ $0.3)$. The minimum $\sigma^{\prime}{ }_{r c}$ value of $0.003 \mathrm{q}_{\mathrm{c}}$ measured on a fully coring pile (with low $A_{r, e f f}$ ) installed in the loose sand deposit at Blessington is significantly lower than load tests on full-scale piles in sand suggest. It is also notably lower than the IC-05 and UWA-05 design lines (see Figure 8).

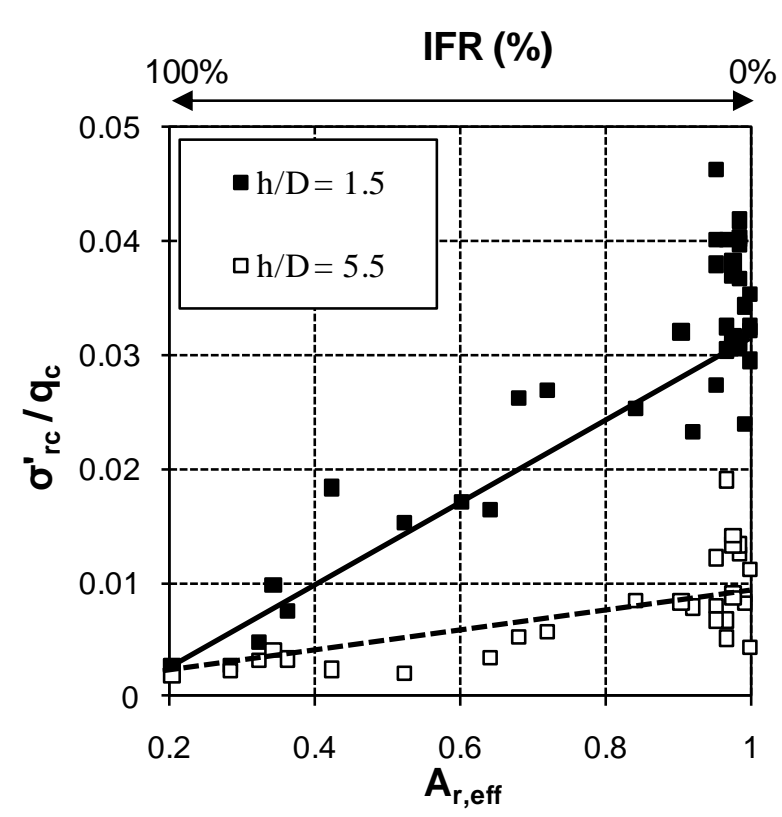

Figure 7. The effect of plugging on radial effective stresses

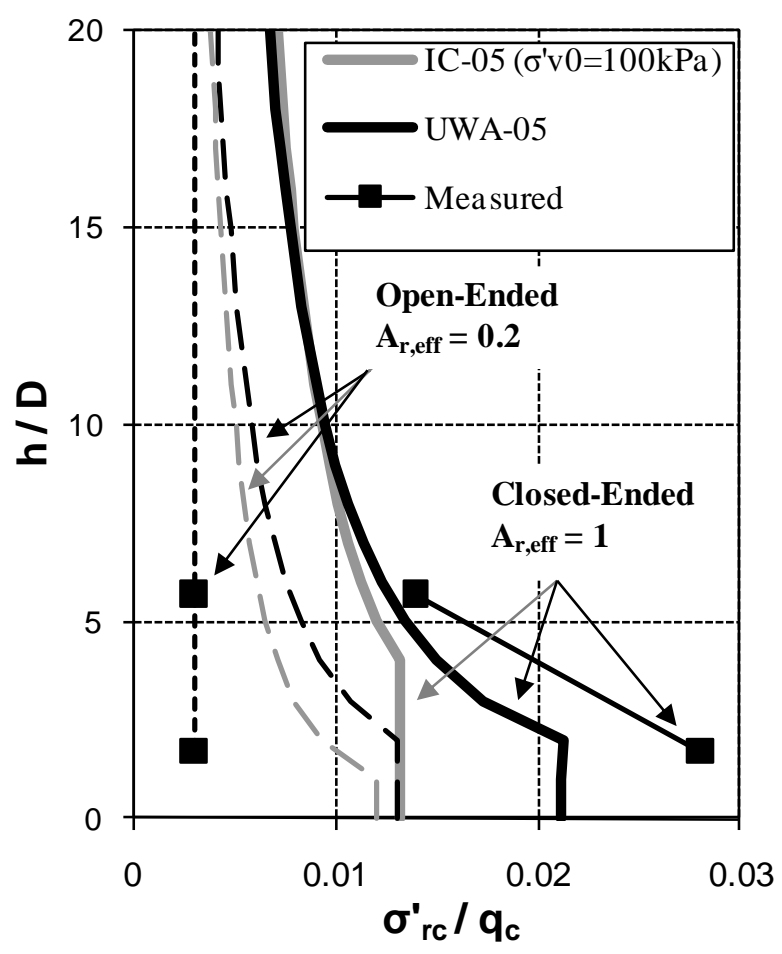

Figure 8. Measured $\sigma^{\prime}{ }_{\text {rc }}$ compared with IC-05 \& UWA-05

\section{CONCLUSIONS}

This paper presents results from the installation of an instrumented open-ended pile in a loose sand deposit. The test provided radial stress measurements as the pile experienced various levels of plugging and soil displacement. The measurements are the first of their kind and this paper aims to highlight the differences between measured radial stresses and assumptions used in recent design methods to extrapolate from closed- to open-ended behaviour. When the pile was fully coring, the equalized radial effective stresses were uniform along the pile shaft relative to the CPT $\mathrm{q}_{\mathrm{c}}$ and no friction fatigue was evi- 
dent. This is contrary to the IC-05 and UWA-05 design methods which maintain an increased stress level near the pile base, even for low-displacement piles. When the pile became plugged, the stresses along the shaft increased, with the biggest increase occurring near the pile tip and reducing further the shaft. The results of these tests suggest that the main difference between the shaft resistance of closedended piles and low-displacement open-ended piles is a result of significantly reduced radial stresses near the pile tip.

\section{REFERENCES}

Bustamante, M. \& Gianeselli, L. 1982. Pile bearing capacity by means of static penetrometer CPT. 2nd European Symposium on Penetration Testing. Amsterdam, pp 493-500.

Chow, F.C. 1997. Investigations into behaviour of displacement piles for offshore structures. PhD Thesis, Civ. Eng. Dept., University of London (Imperial College).

Finlay, T.C., White, D.J., Bolton, M.D. \& Nagayama, T. 2001. Press-in piling: the installation of instrumented steel tubular piles with and without driving shoes. 5th International Conference on Deep Foundations Practice. Singapore, pp 199208.

Foye, K.C., Abou-Jaoude, G., Prezzi, M. \& Salgado, R. 2009. Resistance factors for use in load and resistance factor design of driven pipe piles in sands. Journal of Geotechnical and Geoenvironmental Engineering, Vol. 135, No. 1, pp 113.

Gavin, K.G. \& Lehane, B.M. 2003. The shaft capacity of pipe piles in sand. Canadian Geotechnical Journal, Vol. 40, pp $36-45$.

Igoe, D., Doherty, P. \& Gavin, K.G. 2010. The development and testing of an instrumented model pile. Gotechnical Testing Journal, Vol. 33, No. 2.

Jardine, R.J., Chow, F.C., Overy, R.F. \& Standing, J. 2005. ICP Design Methods for Driven Piles in Sands and Clays. In: Thomas Telford, Ed. London: University of London (Imperial College).

Lehane, B.M. 1992. Experimental investigations of pile behaviour using instrumented field piles. PhD Thesis, Civ. Eng. Dept., University of London (Imperial College).

Lehane, B.M. \& Jardine, R.J. 1994. Shaft capacity of driven piles in sand: a new design approach. Conference on the Behaviour of Offshore Structures. Boston, Mass, pp 23-36.

Lehane, B.M., Schneider, J.A. \& Xu, X. 2005. The UWA-05 method for prediction of axial capacity of driven piles in sand. Frontiers in Offshore Geotechnics: ISFOG. Perth: University of Western Australia, pp 683-689.

Meyerhoff, G. 1956. Penetration tests and bearing capacity of cohesionless soils. Journal of the Soil Mechanics and the Foundations Division, Vol. 82, No. SM1, pp Paper 886, 819.

Paik, K.H., \& Lee, S.R. 1993. Behaviour of soil plugs in openended model piles driven into sands. Marine Georesources Geotech, Vol. 11, pp 353-373.

Uesegi, M. \& Kishida, H. 1986. Influential factors of friction between steel and dry sand. Soils and Foundations, Vol. 26, No. 2, pp 33-46.

White, D.J., Schneider, J.A. \& Lehane, B.M. 2005. The influence of effective area ratio on shaft friction of displacement piles in sand. Frontiers in Offshore Geotechnics, ISFOG. University of Western Australia, Perth.
Xu, X. 2007. Investigation of the end-bearing performance of displacement piles in sand. PhD Thesis, Civ. Eng. Dept. Perth: University of Western Australia. 